\title{
Produção leiteira no Brasil e características da bovinocultura leiteira no Rio Grande do Sul
}

\author{
Dairy production of Brazil and characteristics of dairy cattle \\ in Rio Grande do Sul
}

\author{
Carlos Fernando Jung \\ Faculdades Integradas de Taquara - FACCAT - Taquara - Rio Grande do Sul - Brasil
}

\author{
Alexandre Aloys Matte Júnior \\ Faculdades Integradas de Taquara - FACCAT - Taquara - Rio Grande do Sul - Brasil
}

\begin{abstract}
Resumo: Este artigo apresenta uma revisão sistemática que teve por finalidade evidenciar e analisar as contribuições advindas de pesquisas sobre a produção leiteira no Brasil, em especial, a estrutura da produção da bovinocultura leiteira no estado do Rio Grande do Sul. Para tanto, foram selecionados 28 publicações nas bases Scielo, Periódicos CAPES, Directory of Open Access Journals (DOAJ), e publicações da Embrapa - Pesquisa Agropecuária e Fundação de Economia e Estatística (FEE) do Rio Grande do Sul. O estudo mostrou que $48 \%$ das publicações têm origem na Região Sul do Brasil. As publicações ressaltam a importância da produção de leite para a economia brasileira e para o desenvolvimento social das regiões produtoras. A análise também evidenciou a necessidade de investimentos em qualificação dos meios de produção, recursos humanos e produto final.
\end{abstract}

Palavras-chave: Bovinocultura. Leite. Produção. Agricultura familiar.

\begin{abstract}
This article presents a systematic review that aimed to highlight and analyze the contributions from research on milk production in Brazil, in particular, the structure of the dairy cattle production in Rio Grande do Sul. Therefore, 28 publications were selected in Scielo bases, CAPES Journals, Directory of Open Access Journals (DOAJ), and publications of Embrapa. - Agricultural Research and Fundação de Economia e Estatística (FEE) of Rio Grande do Sul. The study showed that $48 \%$ of publications have originated in southern Brazil. The publications highlight the importance of milk production for the Brazilian economy and the social development of the producing regions. The analysis also showed the need for investments in qualifying the means of production, human resources and final product.
\end{abstract}

Keywords: Cattle. Milk. Production. Family farming. 


\section{Introdução}

O leite é essencial à alimentação humana, sendo produzido em todo o mundo. A importância pode ser observada no ambiente produtivo e econômico mundial, principalmente em países considerados em desenvolvimento e em sistemas de agricultura familiar. Nas últimas três décadas, a produção mundial de leite aumentou mais de $50 \%$, chegando a 769 milhões de toneladas em 2013 (FAO, 2016).

Segundo a Food and Agriculture Organization of the United Nations (2016), órgão da ONU, aproximadamente 150 milhões de lares em todo o mundo estão envolvidos na produção leiteira, sendo característica da maioria dos países em desenvolvimento a produção a partir de pequenos agricultores, pois fornece retorno rápido aos produtores de pequena escala.

O continente asiático tem apresentando crescimento exponencial desde a década de 70, sendo considerado como "motor" da produção leiteira. O Brasil é o $5^{\circ}$ maior produtor de leite em nível internacional, ficando apenas atrás da Índia, Estados Unidos da América, China e Paquistão (FAO, 2016). É importante salientar também a participação de países como a Nova Zelândia, Uruguai e Argentina no mercado leiteiro (CORRÊA et al, 2010). A atuação de cooperativas em países com elevada produção de leite merece destaque. Por exemplo, na Nova Zelândia a participação de cooperativas na produção chega a 95\% e nos Estados Unidos da América a 83\% (SCHUBERT et al, 2009).

No Brasil, o leite é um dos seis produtos mais importantes da agropecuária brasileira, sendo essencial no suprimento de alimentos e na geração de emprego e renda para a população (EMBRAPA, 2016). Corrêa et al (2010) e Souza et al (2009) afirmam que desde o início da década de 90, a atividade leiteira tem passado por grandes transformações no nosso país, buscando tornar-se competitivo e inovador no mercado global, focando na produção em escala com qualidade, agregação de valor e industrialização de produtos diferenciados.
Conforme levantamento do Instituto Brasileiro de Geografia e Estatística (IBGE) referente ao ano de 2014, a produção leiteira chegou a marca de 35,17 bilhões de litros, sendo a região Sul a maior produtora do país, representando $34,7 \%$ do total nacional. Durante o mesmo período, o Estado de Minas Gerais permaneceu como maior produtor Brasileiro, seguido do Rio Grande do Sul e Paraná. Além disso, o país possui o segundo maior rebanho bovino a nível mundial, atrás apenas da Índia (MILKPOINT, 2015).

Como característica peculiar, a produção leiteira nacional conta com grande diversidade estrutural. A heterogeneidade demonstra-se tanto nos sistemas de produção à aspectos ligados a alimentação do rebanho e qualidade do leite (CORRÊA et. al, 2010; SOUZA et al, 2009). Conforme Oliveira et. al (2007), a elevada diversidade socioeconômica, cultural e climática que caracteriza os sistemas de produção geram a necessidades de estudos regionais sobre a produção leiteira, colaborando com isso o fato de que a pecuária desse segmento evidencia-se em mais de $80 \%$ dos municípios brasileiros. Assim, novos estudos sobre este setor são necessários para se obter uma caracterização da produção leiteira no Brasil e suas particularidades.

Principalmente na Região Sul do Brasil, destaca-se o sistema de produção familiar. Consoante à Berro et al (2014) a produção de leite consolidou-se como atividade âncora na composição da renda dos pequenos agricultores, impactando no desenvolvimento regional, principalmente por fatores ligados a absorção de mão de obra, grande alcance social e agregação de valor na propriedade, possibilitando o uso de terras de qualidade inferior para o desenvolvimento dessa atividade. Conforme Schubert et al. (2009) a cadeia produtiva leiteira de base familiar mostra-se promissora, levando em conta as previsões de que o Brasil apresente crescimento nesse setor, e também a capacidade de rápida adaptação e reconversão produtiva desse sistema.

Esse artigo tem por objetivo evidenciar e analisar as contribuições advindas de pesquisas focadas na produção leiteira nacional, aprofundando- 
se nas características da bovinocultura leiteira, em especial, no estado do Rio Grande do Sul. O restante deste artigo está organizado da seguinte forma: a seção 2 apresenta os procedimentos metodológicos da pesquisa, a seção 3 a revisão de literatura, na seção 4 são apresentadas as discussões e os resultados obtidos a partir da revisão sistemática e a seção 5 conclui o estudo.

\section{Procedimentos metodológicos}

Este artigo de revisão sistemática reúne contribuições sobre a produção leiteira do Brasil e características da bovinocultura no país e no estado do Rio Grande do Sul, buscando detalhes sobre a estrutura organizacional e produtiva da cadeia láctea na unidade da federação. Conforme Creswel (2010) pesquisas dessa natureza cumprem vários propósitos, compartilhando e relacionando estudos já realizados, proporcionando referência para comparação com outros resultados.

Nesta pesquisa foram utilizados quatro critérios para coleta de dados, sendo que para que o artigo integre essa revisão: (i) conter a expressão "leite", "leiteira (o)" ou "laticínio(s) no título; (ii) conter as expressões "produção" ou "produtor (es)" em qualquer parte do trabalho; (iii) ter sido publicado em inglês, português ou espanhol; e (iv) ser uma publicação científica. Esta pesquisa não estabeleceu restrições ao ano de publicação dos artigos, teses, dissertações e outras publicações.

Os critérios para inclusão foram aplicados sobre as seguintes bases de dados: (i) Scielo, (ii) Periódicos CAPES, (iii) Directory of Open Access Journals (DOAJ), (iv) Pesquisa Agropecuária Embrapa e (v) Publicações da Fundação de Economia e Estatística (FEE) do Rio Grande do Sul. Isso permitiu, em um primeiro momento, a inclusão de aproximadamente dois mil trabalhos que satisfaziam os critérios de inclusão. Realizada uma triagem foram descartados os estudos que não apresentavam conteúdos relevantes ao objetivo da pesquisa. Desta forma, restaram 28 publicações para a realização desta revisão sistemática.
A partir da leitura e análise inicial das publicações selecionadas, foi elaborada uma planilha destinada a organizar as seguintes informações: (i) ano; (ii) título; (iii) autores; (iv) palavras-chave; (v) periódico ou base de dados; (vi) local de origem da publicação; e (vii) área de publicação. Para classificação das publicações selecionadas em relação à área de publicação, levou-se em consideração a área de conhecimento do periódico.

Após a classificação, as publicações foram analisadas e extraídos os principais resultados. Na sequência, foram relacionadas as percepções e contribuições dos autores, sendo que os conteúdos em síntese referem-se a: (i) caracterização da produção leiteira em âmbito mundial e nacional; (ii) caracterização das propriedades e os produtores no Rio Grande do Sul e (iii) evolução das políticas agrícolas para o setor.

Para melhor visualização dos resultados foi elaborado um quadro que relaciona em ordem cronológica o ano de publicação, os autores das publicações e o foco da pesquisa. Além disso, foram construídos gráficos onde são demonstradas as origens das publicações (em função dos Estados brasileiros), o ano em que as pesquisas foram publicadas e a área de publicação.

\section{Resultados}

O Quadro 1 apresenta uma síntese das publicações, em ordenação cronológica, que foi utilizada para a revisão da literatura. Esse quadro relaciona a origem de cada publicação à área de publicação. 
Quadro 1 - Síntese das publicações no período 1998-2015

\begin{tabular}{|c|c|c|c|}
\hline Ano & Autor & País & Área de Publicação \\
\hline 1998 & CASTRO, C. C. et al & BRASIL & Agropecuária \\
\hline 2002 & PORTELA, J. N. et al & BRASIL & Ciências Agrárias \\
\hline 2003 & COUTO, A. T. & BRASIL & Geografia \\
\hline 2004 & $\begin{array}{l}\text { FERNANDES, E .N; BRESSAN, } \\
\text { M.; VERNEQUE, R. S. }\end{array}$ & BRASIL & Ciências Agrárias \\
\hline 2004 & GONZALEZ, H. L. et al & BRASIL & Zootecnia \\
\hline 2004 & $\begin{array}{l}\text { WAGNER, S. A.; GEHLEN, I.; } \\
\text { WIEST, J. M. }\end{array}$ & BRASIL & Ciências Agrárias \\
\hline 2004 & BUENO, P. R. B. et al & BRASIL & Zootecnia \\
\hline 2005 & NETO, B. S.; BASSO, D. & BRASIL & Desenvolvimento Econômico \\
\hline 2005 & $\begin{array}{l}\text { MONTOYA, M.; FINAMORE, E. } \\
\text { B. }\end{array}$ & BRASIL & Economia \\
\hline 2005 & SÁ, C. O. et al & BRASIL & Agropecuária \\
\hline 2006 & FRANÇA, F. M. C. et al & BRASIL & Agropecuária \\
\hline 2006 & ZANELA, M. B. et al & BRASIL & Zootecnia \\
\hline 2006 & NORO, G. et al & BRASIL & Zootecnia \\
\hline 2008 & POPESEU, A.; ANGEL, E. & ROMÉNIA & Zootecnia \\
\hline 2008 & NÚÑEZ, S. R.; HUELVA, D. C. & VENEZUELA & Agropecuária \\
\hline 2008 & SILVA, H. A. et al & BRASIL & Ciências Agrárias \\
\hline 2009 & GOBBI, W. A.; PESSOA, V. L. & BRASIL & Geografia \\
\hline 2010 & $\begin{array}{l}\text { MONTOYA, M.; FINAMORE, E. } \\
\text { B. }\end{array}$ & BRASIL & Economia \\
\hline 2011 & JANTSCH, E. M. et al & BRASIL & Agropecuária \\
\hline 2011 & POPESEU, A. & ROMÊNIA & Zootecnia \\
\hline 2011 & CASARI, P.; TORMEM, P. & BRASIL & Agropecuária \\
\hline 2011 & SILVA, D. A. R. et al & BRASIL & Ciências Agrárias \\
\hline 2011 & SILVEIRA, I. D.B. et al & BRASIL & Zootecnia \\
\hline 2012 & $\begin{array}{l}\text { LOPES, M. A.; SANTOS, G..; } \\
\text { CARVALHO, F. M. }\end{array}$ & BRASIL & Ciências Agrárias \\
\hline 2013 & RODRIGUES, L. G.; ALBAN, L. & BRASIL & Administração de Empresas \\
\hline 2013 & MAIA, G. B. S. et al & BRASIL & Agropecuária \\
\hline 2015 & COSTA, V. S. et al & BRASIL & Ciências Contábeis \\
\hline 2015 & FAUTH, E. M.; FEIX, R D. & BRASIL & Desenvolvimento Econômico \\
\hline
\end{tabular}

Fonte: Elaborada pelo autor.

A análise mostra uma concentração de publicações no período de 2004 a 2008. No entanto, entre 2010 e 2015 as publicações correspondem a $39,29 \%$ dos trabalhos selecionados. Isto deve-se ao fato que no ano de 2011 um maior número de estudos foram publicados, ver Figura 1.
Figura 1 - Número de publicações por ano

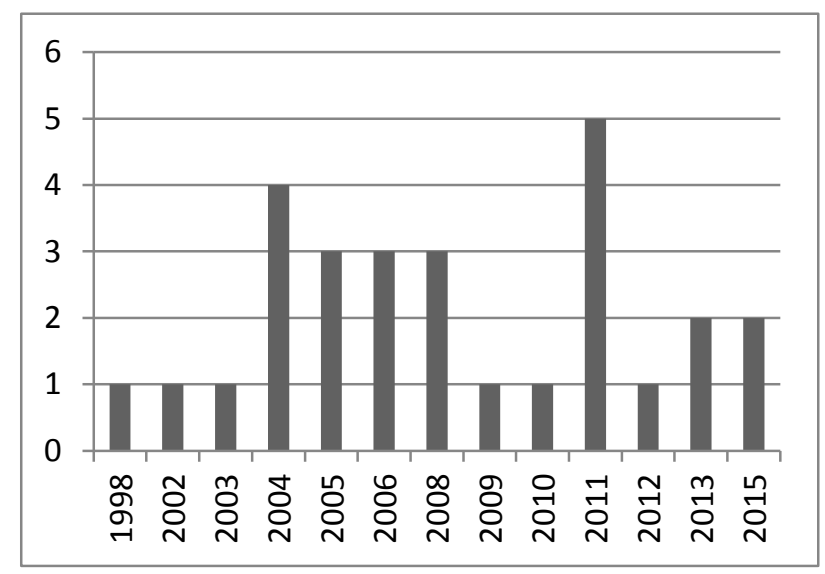


Levando-se em conta as 25 publicações provenientes do Brasil destaca-se que 48,00\% dos trabalhos concentram-se em Estados da Região Sul do país e dizem respeito, por exemplo, à pesquisas sobre melhorias na qualidade do leite, tipos de rebanhos e sobre o sistema de agricultura familiar, predominante em toda a porção, ver Figura 2. As principais contribuições sobre estes temas encontrase em autores como Montoya e Finamore (2010), Rodrigues e Alban (2013), e Casari e Tormem (2011). A região Sudeste, concentra $36 \%$ das publicações, evidenciando interesse especial das regiões Sul e Sudeste pelo tema, já que as demais regiões brasileiras registram apenas $16 \%$ de concentração.

\section{Figura 2 - Número de publicações por Estado do Brasil}

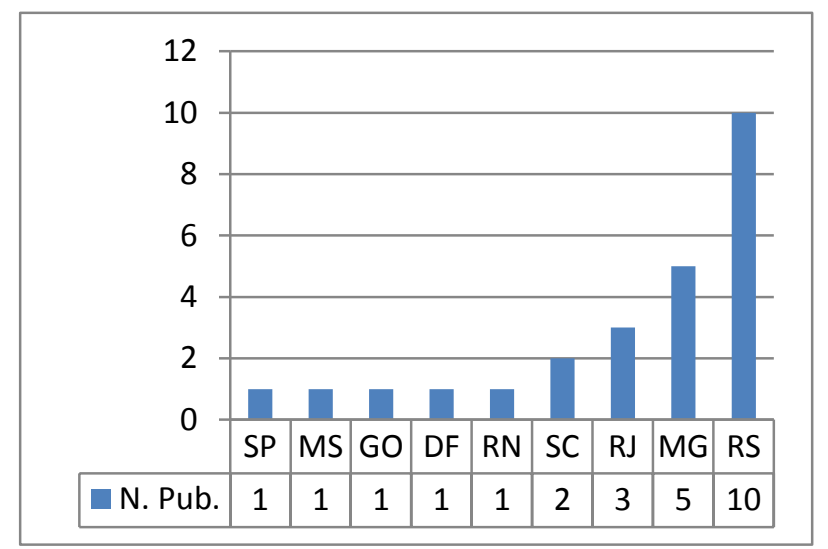

A Figura 3 mostra que a maioria dos trabalhos foram publicados nas áreas de Zootecnia (25\%), Agropecuária (21,42\%) e Ciências Agrárias (21,42\%), indicando o quanto a necessidade de conhecimento da atividade leiteira e seus aspectos, como manejo de rebanho, nutrição e uso estratégico da propriedade rural são relevantes.

Destacam-se também as áreas de Desenvolvimento Econômico, Ciências Contábeis, Economia e Administração de Empresas, que juntas representam $25 \%$, o que evidencia a necessidade de uma gestão qualificada nas propriedades rurais com o objetivo de desenvolver o potencial da produção leiteira e o consequente desenvolvimento econômico. Corroboram com isso os artigos de Bueno et al (2004), Silva et al (2008), Wagner, Gehlen e Wiest
(2004), Zanela et al (2006) Costa et al (2015), e Lopes, Santos e Carvalho (2012).

Figura 3 - Número de publicações por área de interesse

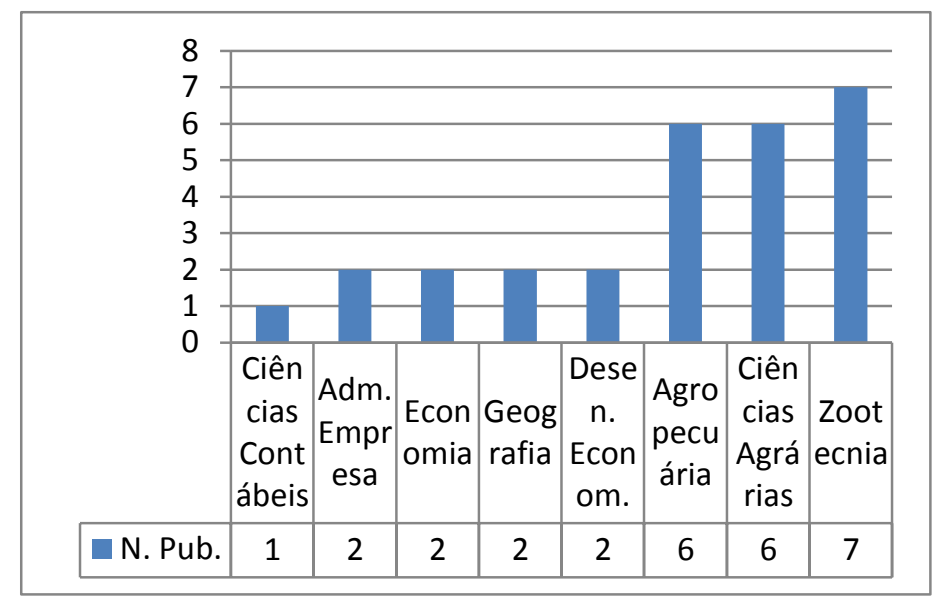

\section{Análise e discussão}

\subsection{Produção mundial de leite e informações sobre o Brasil}

O leite é produzido em todo mundo, porém, valendo-se de diferentes sistemas de produção e em propriedades que podem ser pequenas, médias ou grandes (COSTA et. al, 2015). Rodrigues e Alban (2013) afirmam que a produção mundial de leite provém $85 \%$ da bovinocultura, sendo outra peculiaridade desse mercado o pouco volume transacional entre países, cerca de apenas 5\% a 7\% da produção global. Outra característica do mercado lácteo global, conforme Núñez e Huelva (2008) é que $75 \%$ do consumo se concentra em apenas 20 países.

Neto e Basso (2005) afirmam que países competitivos como Nova Zelândia e Austrália adotam modelos de produção próprios, diferentes de outros grandes produtores, como Estados Unidos e Canadá, o que sugere que cada país pode desenvolver ou adaptar o modelo de acordo com determinados objetivos e características.

Os maiores produtores da União Europeia são a Alemanha, França, Reino Unido, Polônia, Holanda, Itália, Espanha, Irlanda, Romênia e Dinamarca, produzindo em conjunto $82,82 \%$ do leite bovino da 
União Europeia. O rebanho estimado é de 29 milhões de vacas leiteiras, responsáveis pela produção de cerca de 140 bilhões de litros de leite ao ano (POPESCU, 2011). Já os Estados Unidos possuem um rebanho de cerca de 9 milhões de vacas leiteiras, produzindo cerca de 90 bilhões de litros de leite por ano. Tal produtividade pode ser explicada pela alta tecnologia empregada na produção leiteira. Suas fazendas possuem em média cerca de 147 vacas leiteiras, variando por região do país, estando as maiores propriedades localizadas no Oeste americano. Os estados com maior produção de leite são a Califórnia, Wisconsin, Nova Iorque, Idaho e Pensilvânia, representando $53,39 \%$ da produção total do país (POPESCU, ANGEL, 2008).

A produção leiteira brasileira é baixa em comparação a outras grandes nações que ocupam os primeiros lugares do ranking de produção, onde, por exemplo, os Estados Unidos da América conseguem obter 7.953 litros de leite por vaca/ano, enquanto que no Brasil a média alcançada é de 1.154 litros vaca/ano. Para Bueno et al (2004) isto demonstra a necessidade da utilização de tecnologias e cuidados com a alimentação do rebanho, que poderá impactar diretamente na produtividade. Em relação à participação no MERCOSUL, o Brasil lidera os índices de produção de leite, seguido pela Argentina, Uruguai e Paraguai (RODRIGUES, ALBAN, 2013). A exportação brasileira também é baixa, tendo como destino países africanos e da América Latina, uma vez que os padrões de qualidade da produção nacional estão aquém das exigências da União Europeia e Estados Unidos (MAIA et al, 2013).

A atividade leiteira pode ser considerada uma das mais importantes da agropecuária brasileira já que está presente em cerca de 1,3 milhões de propriedades no país (SILVA et al, 2011). Segundo Costa et al (2015) o setor de leite e derivados possui grande volume na geração de empregos, superando áreas como a construção civil e indústria de automóveis por exemplo, o que acaba sendo fato gerador de renda. Salientam os autores que para cada $R \$ 1$ milhão em produtos demandados o leite gere 197 empregos, superando os demais setores.
Fazendo um comparativo entre os anos de 1980 e 2005, Casari e Tormem (2011) demonstram que a produção de leite no Brasil teve aumento de $109,10 \%$ entre esse período, um crescimento médio anual de $4,20 \%$, justificado em partes pelo aumento do número de vacas ordenhadas que passou de 16.513 para 20.820 entre 1980 e 2005.

Ainda, Fernandes, Bressan e Verneque (2004) citam que a produção de leite brasileira cresceu de $36,5 \%$ na década de 90, concentrando-se principalmente nas regiões Sul e Sudeste. Colaborando com esse acréscimo, o aumento da produtividade dos animais, pois uma vaca que em 1974 produzia uma média de 655 litros de leite/ano passou a produzir 1381 litros leite/ano em 2011 (MAIA et al, 2013). De acordo com Rodrigues e Alban (2013) o Brasil era importador de leite até o ano de 2004, quando passou a ser autossuficiente graças ao aumento constante de sua produção. Porém, apesar de incremento nos índices produtivos, sob ponto de vista de Gobbi e Pessoa (2009), o setor leiteiro brasileiro enfrenta dificuldades em ser competitivo principalmente em produtividade, qualidade e eficiência.

Paralelamente a esses aspectos, o consumidor brasileiro tem se tornado mais exigente em relação à qualidade dos produtos lácteos oferecidos, e, buscando atender essa demanda, a indústria láctea brasileira tem buscado modernizar-se, exigindo dos produtores um leite de melhor qualidade, buscando competitividade com produtos importados (GONZALEZ, 2004).

Em estudo realizado, Zanela et al (2006) citam que a maioria dos produtores leiteiros brasileiros, cerca de $66,6 \%$ produz até 50 litros por dia, o que equivale a $30,2 \%$ da produção nacional, o restante dos produtores gera quantidades acima de 50 litros diários e representam o saldo da produção nacional diária. Lopes, Santos e Carvalho (2012) referem que nos sistemas de produção adotados no Brasil a busca é por animais de maior produtividade, gerando uma maior ocorrência de sistemas de confinamento total (responsável por 50\%), seguido pelo 
semiconfinamento (33\%) e o restante (17\%) dos sistemas baseados em pastagens.

Como fator que dificulta a qualificação do leite brasileiro, Couto (2003) cita o grande atraso histórico do Brasil na produção leiteira, o que gera atualmente necessidade urgente de mudança em relação às exigências de abertura de novos mercados, sugerindo mudanças do sistema de processamento à distribuição. O produtor, por falta de conhecimento, acaba por acreditar que a produção de leite com qualidade superior é possível somente com uso de tecnologia, na maioria das vezes cara, o que não é verdade, uma vez que é possível produzi-lo com tecnologia simples e de baixo custo, levando à necessidade de elaboração de programas de capacitação de produtores, possibilitando acesso ao conhecimento e técnicas de produção adequadas (MAIA et al, 2013). Porém, para Silveira et. al (2011), tem surgido uma nova realidade na atividade leiteira, uma vez que os produtores tem se conscientizado sobre a necessidade de uma administração eficiente de sua atividade, tornando-se mais competitivos e buscando maior rentabilidade e qualidade do produto oferecido.

Outro fato a ser destacado é de que o Brasil vem recebendo pequenos incrementos também na produção de leite de cabra, principalmente na região Nordeste do país. Conforme França et al (2006) delineiam em seu trabalho, o leite de cabra tem grande apreço no exterior, principalmente no continente europeu, mas no Brasil ainda não possui grande significado como bem econômico. A produção citada no trabalho dos autores abrange o estado do Rio Grande do Norte, onde a produção ocorre com grande apoio e subsídio de programas do governo federal.

Situação similar é constatada no estudo de Sá et al (2005), realizado no Sergipe, onde os agricultores, em sua maioria provenientes de estruturas familiares em busca de uma fonte de renda extra, são subsidiados por programa do governo do estado. Em ambas as situações, os autores explicitam as dificuldades enfrentadas pelos produtores de leite de cabra, principalmente fatores ligados a alimentação e enfrentamento do período de secas.

A partir da década de 1990, o desenvolvimento da exploração da bovinocultura leiteira foi intenso devido a liberação total dos preços do leite pelo governo federal e a criação do MERCOSUL, colaborando também a adoção do plano Real, que proporcionou poder de compra à população brasileira, impactando no consumo de lácteos. As políticas nacionais implantadas tinham intenções como a desregulamentação do sistema do mercado, a abertura comercial e estabilização econômica, promovendo a reestruturação geográfica da produção, a redução de produtores, concorrência com produtos importados (gerando uma guerra de preços nas prateleiras), e ganho de poder dos laticínios e multinacionais, além do aumento de escala de produção, focada em grande produção (COSTA et al, 2015; MONTOYA, FINAMORE, 2005, 2010; ZANELA et al, 2006).

Durante esse período, a articulação entre produtores e a indústria processadora sofreu impacto com essas mudanças, chegando em muitos casos a uma integração vertical total, principalmente pela atuação das indústrias lácteas, controlando e coordenando a produção de leite natural, e os produtores de outro lado, industrializando sua produção (MONTOYA, FINAMORE, 2005). A série de mudanças impostas pelo padrão tecnológico moderno durante a década de 1990 gerou um processo de exclusão de cerca de 107.000 pequenos produtores familiares na cadeia do leite, correspondente a $56,24 \%$ do número total de produtores presentes no mercado, enquanto que observou-se no Rio Grande do Sul, em meio ao mesmo processo de modernização, houve a redução do número de produtores em 26,85\%, devendo-se essa discrepância ao fato de que os produtores gaúchos organizaram-se em cooperativas regionais, garantindo comercialização do leite mesmo em pequena escala (WAGNER, GEHLEN, WIEST, 2004; MONTOYA, FINAMORE, 2010).

Atualmente, a cadeia se estrutura basicamente através da venda do leite de produtores primários aos 
laticínios, que por sua vez o utilizam para a fabricação de diversos produtos lácteos. Costa et al (2015) valese de argumentos relacionados a importância de um sistema qualificado de comercialização da produção, expressando tal necessidade ao vincular o setor produtivo e os consumidores finais, sendo sua avaliação necessária para a elaboração de estratégias. Na maioria das vezes, existem poucos laticínios em uma região, sendo que este pode ser o único comprador de leite dessa determinada localidade. A atuação de cooperativas também tornase fundamental a atual cadeia produtiva, uma vez que o conjunto de atividades realizadas pelas cooperativas leiteiras brasileiras varia bastante, passando desde os objetivos de negociação coletiva, compra de insumos, à atividades como o beneficiamento do leite em plantas próprias (MAIA et al, 2013).

\subsection{A Região Sul e a agricultura familiar}

Para Couto (2003) a Região Sul do Brasil é uma das principais produtoras de leite do Brasil, com grande presença da agricultura familiar como principal sistema de produção, em grande parte devido à colonização europeia. Gobbi e Pessoa (2009) aprofundam essa questão afirmando que, trazendo modos de produção de seus países de origem, a influência de colonizadores europeus também permite observar nessa região uma maior difusão de modernização da agricultura e de estruturas de organização, como o cooperativismo e associativismo, além de maior facilidade na captação de recursos e créditos governamentais do que em regiões que também apresentam grande número de estabelecimentos familiares de agricultura, como o Nordeste.

As mesorregiões do sudoeste do Paraná, oeste de Santa Catarina e noroeste do Rio Grande do Sul respondem por mais da metade da produção de leite da Região Sul do Brasil, principalmente por contarem com características propícias ao desenvolvimento da atividade leiteira (FAUTH, FEIX, 2015). Algumas dessas características privilegiadas estão relacionadas a sua latitude, permitindo o uso de diversas espécies bovinas, o que facilita a adoção do sistema de pastagem, que é mais econômico (SILVA et al, 2008). A produção de leite tornou-se atividade indispensável para a composição de renda de um número expressivo de produtores, onde, através de afirmações destes, a atividade leiteira caracteriza-se como a que possui maior rentabilidade para sua propriedade (CASARI, TORMEM, 2011).

Tais colaborações permitem auferir a importância da estrutura da agricultura familiar para a produção de leite na região Sul do Brasil. Como características da agricultura familiar, Neto e Basso (2005), Couto (2003) e Gobbi e Pessoa (2009) definem que esta caracteriza-se pela família ser proprietária da terra e dos meios de produção, assumindo o trabalho no seu estabelecimento produtivo, assegurando-se a alimentação da família através do próprio processo de diversificação de cultivo. O tamanho da propriedade é estabelecido pelo que a família pode explorar com base em seu próprio trabalho, associado a tecnologias e meios dos quais dispõe (NETO, BASSO, 2005).

Em 2006, os estabelecimentos de agricultura familiar eram responsáveis por $58 \%$ do total de leite produzido nesse ano, demonstrando a importância das pequenas escalas produtivas para o cenário nacional do leite (MAIA et al, 2013). Para Gobbi e Pessoa (2009), a partir da década de 90 a agricultura familiar passou a receber reconhecimento em relação a sua importância para a geração de renda, emprego e melhorias da população rural. Ainda, o acréscimo na produção da agricultura em um determinado território sempre resulta na ampliação da renda e em melhores condições à população daquela região, o que pode ser aplicado a questão da agricultura familiar (NETO, BASSO, 2005)

A conquista de mercado por parte dos produtores de base familiar gera impacto favorável principalmente as regiões do interior do país, evitando o êxodo rural através da geração de trabalho e renda, tornando-se um instrumento de desenvolvimento social (GOBBI, PESSOA, 2009). Wagner, Gehlen e Wiest (2004) defendem a sustentabilidade produtiva 
do modelo de base familiar, independente da tecnologia adotada pelo grupo, principalmente em virtude da diversificação de fontes de renda, através de outras criações e culturas, o que dá amparo para que permaneçam nesse modelo e no meio rural.

Neto e Basso (2005) afirmam que é possível enxergar a diferença proporcionada pela geração e divisão de renda em áreas com predominância da pecuária e agricultura familiar, onde também ocorre um fácil acesso a terra. Nessas regiões com predominância da agricultura familiar, a produção leiteira constitui-se como uma atividade básica, principalmente em pequenas e médias propriedades. Segundo a percepção de Costa et al (2015) a produção leiteira na ótica da agricultura familiar, em sua maioria, não utiliza critérios ligados a rentabilidade econômica, as decisões são baseadas em experiências pessoais dos empresários rurais, limitando o uso racional de recursos. Por outro lado, Gobbi e Pessoa (2009), afirmam que os agricultores de base familiar se mostram mais eficientes que os agricultores patronais e de grande escala, uma vez que produzem mais com menos recursos provenientes de créditos rurais.

Um dos motivos dos pequenos produtores organizarem-se em relação à produção leiteira é o fato de que essa cultura é adaptável a diferentes condições ecológicas, mudanças climáticas e socioeconômicas, pois permite a viabilidade através de diferentes escalas e sistemas de produção, diferente de outras produções animais, como a suinocultura e avicultura, onde se pressupõe a existência de estruturas tecnologias e exigências de agroindústrias receptoras da produção (NETO, BASSO, 2005; GOBBI,PESSOA, 2009). Como forma de minimizar impactos e promover uma forma mais organizada de participação no mercado, Costa et al (2015) destacam a organização dos produtores, principalmente os que utilizam base familiar de produção, através de cooperativas, centralizando a produção e proporcionando maior poder de venda e negociação junto a compradores e vendedores de insumos, necessários ao manejo do rebanho.

\subsection{A cadeia produtiva do RS e suas características}

A cadeia do leite do Rio Grande do Sul é uma grande produtora nacional, contando com processos de produção modernos, sendo identificada como uma das mais eficientes do Brasil, inclusive, respondendo por aproximadamente 7\% do PIB do agronegócio do Rio Grande do Sul. Seu desempenho é muito importante para o desenvolvimento econômico estadual, já que possui um encadeamento forte com o setor urbano (MONTOYA, FINAMORE, 2010). Fauth e Feix (2015) citam dados provenientes da RAIS referentes a 2013 para afirmar que o conjunto das atividades da indústria de laticínios é responsável por empregar cerca de 9484 pessoas no Rio Grande do Sul, representando 1,3\% do emprego industrial nesse Estado, e 7,7\% do emprego da indústria de laticínios no Brasil.

Nas últimas décadas a produção leiteira do Rio Grande do Sul aumentou em todas as regiões, valendo-se de ganhos em relação a produtividade, ver Figura 4. Em 2012, a Mesorregião Noroeste já respondia por dois terços da produção estadual, contando também com aumento do rebanho, enquanto que as demais regiões estabilizaram ou reduziram a quantidade de vacas leiteiras (FAUTH, FEIX, 2015).

\section{Figura 4 - Evolução da produção leiteira em regiões do $\mathrm{RS}$}

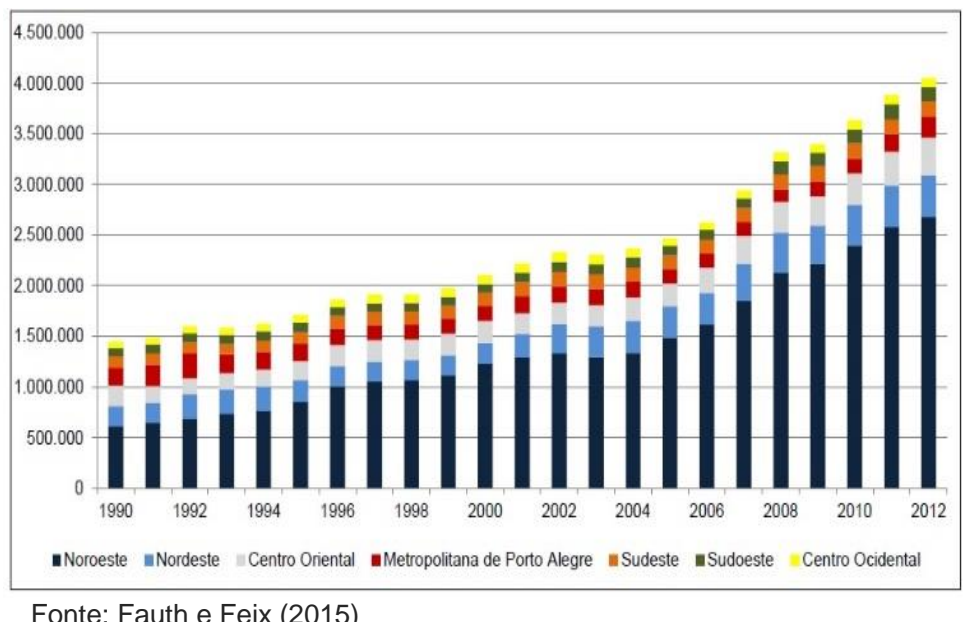

Fonte: Fauth e Feix (2015) 
A produção de leite natural gaúcha é quase que integralmente destinada para a indústria de leite beneficiado, produtora de bens finais, apresentando assim mínima interligação com outras indústrias do ramo alimentício, demonstrando autonomia no suprimento de insumos. Além disso, a indústria abastece o mercado estadual e é exportadora de líquidos para outros estados brasileiros, evidenciando a posição de vantagem competitiva do Rio Grande do Sul (MONTOYA, FINAMORE, 2005).

Noro et al (2006) salientam que a produção tem crescido em escala e produtividade nos últimos anos, grande parte em bacias leiteiras ligadas a cooperativas, que são responsáveis pela maioria da captação do leite. É uma atividade predominante em pequenas propriedades no Rio Grande do Sul, sendo que a maior parte provém de estabelecimentos com área aproximada de 20 hectares (CASTRO et al, 1998).

Em pesquisa realizada, Portela et al (2002) mostram que as propriedades leiteiras do Rio Grande do Sul, em média, apresentam rebanho composto por 7 vacas dispostas em propriedades de 11 ha, produzindo $24,5 \mathrm{~kg}$ de leites por dia, estando integradas no desenvolvimento de outras culturas, sendo este fato essencial para a manutenção de algumas unidades onde predominam a estrutura familiar, permitindo menor escala de produção e possibilitando a maior facilidade na absorção de crises de mercado, entre outras características.

De acordo com Neto e Basso (2005), através do aumento de escala de produção leiteira na década de 90 , viabilizada pela crise na soja e alta demanda do leite, muitos agricultores operantes no sistema de agricultura familiar acabaram declinando da atividade leiteira, principalmente por considerarem inviáveis as alterações e exigências tecnológicas e sanitárias das indústrias de laticínios. Porém, com a recuperação da rentabilidade da soja no final da década de 90, grandes produtores voltaram sua atenção novamente a produção de grãos e os pequenos produtores voltaram a cena abastecendo o mercado lácteo.

Neto e Basso (2005) afirmam ainda que no Rio Grande do Sul predominam dois sistemas agrários, sendo a pecuária extensiva nas áreas de campo e a produção através da agricultura familiar em áreas com predominância de floresta. Justamente, as regiões com maior produção de leite no estado são onde predominam sistemas de agricultura familiar, em regiões com origens coloniais. A produção ocorre em pequenas propriedades de cunho familiar em virtude de que a produção em grande escala de leite não se torna interessante a produtores que possuem grandes porções de terra, sendo que estes dão preferência ao cultivo extensivo de grãos em detrimento do leite. Assim, os grandes agricultores são muito menos estáveis na bovinocultura do leite (NETO, BASSO, 2005).

Em estudo conduzido por Wagner, Gehlen e Weist (2004), que teve como objetivo identificar o padrão tecnológico, organização sistêmica da propriedade, inserção no mercado entre outras características de algumas propriedades localizadas no RS, concluindo que os produtores aumentaram a produtividade e qualidade do leite através de investimentos realizados na década de 90 em virtude das transformações ocorridas no mercado, no comportamento dos consumidores e no âmbito tecnológico. Porém, a generalização de propriedades e condições de aumento da escala recomendados pelas grandes indústrias de leite teria um efeito ruim tanto socialmente quanto economicamente para ao desenvolvimento rural, tirando os pequenos produtores e grupos familiares do mercado (NETO, BASSO, 2005)

Como demonstrado na Figura 4, a região Noroeste do RS é responsável por grande parte do leite produzido no RS (NORO et. al 2006; JANTSCH et al, 2011; ZANELA et al, 2006). A região apresenta características de multifuncionalidade, uma vez que um indivíduo realiza diversas funções dentro da propriedade, levando em conta que existem diferentes tipos de produção na região, frisando-se sistemas onde predomina a diversificação, produzindo-se leite mas ao mesmo tempo plantandose milho, soja, pastagens, sistemas que dividem espaço com a suinocultura, avicultura e também sistemas focados apenas na atividade leiteira 
(JANTSCH et al (2011). Segundo Fauth e Feix (2015), com a saída de várias cooperativas leiteiras da região na última década, tendo estas partido para a cadeia de grãos, a alternativa encontrada pelos produtores locais foi a de se organizar em cooperativas menores, a fim de gerar vantagens na comercialização da matéria-prima para a indústria de laticínios.

Sobre políticas de apoio a atividade leiteira e a agricultura em pequenas propriedades, Jantsch et al (2011) citam a existência do programa Rede Leite, que atende esse público em alguns municípios da região Noroeste do Rio Grande do Sul. Fauth e Feix (2015) citam a criação do Fundo de Desenvolvimento da Cadeia Produtiva do Leite do Rio Grande do Sul (Fundoleite-RS) em 2013. Este fundo tem por objetivo promover o fortalecimento entre setores público e privado da cadeia produtiva leiteira, gerar qualificação na produção de leite, ampliar os mercados consumidores de leite e produtos lácteos e melhorar a renda de agricultores familiares inseridos na atividade leiteira. As receitas para este fundo são obtidas a partir de cobrança de taxas sobre a quantidades produzidas por laticínios. Já Costa et al (2015) e Maia et al (2013) destacam como política pública de apoio do governo aos produtores leiteiros o Programa Nacional de Fortalecimento da Agricultura Familiar (PRONAF), disponível a nível nacional, oferecendo taxas de juro variável entre $0,5 \%$ a.a.

Como apoio a produção leiteira, Maia et al (2013) referem que foi realizado um desembolso de cerca de $R \$ 690$ milhões para modernização e construção de unidades de beneficiamento de leite em cooperativas envolvidas na cadeia leiteira e o Programa de Garantia de Preços para a Agricultura Familiar (PGPAF). Este apoio tem oportunizado às famílias que utilizam o PRONAF um desconto no pagamento do financiamento em caso de baixa de preços no mercado, garantindo que possam continuar trabalhando.

Além disso, destaca-se o programa Balde Cheio, desenvolvido pela Empresa brasileira de Pesquisa Agropecuária (EMBRAPA), que tem como objetivo a transferência de tecnologia de produção a produtores de leite. Também são desenvolvidos programas ligados ao mercado internacional, principalmente por meio de medidas antidumping contra a União Europeia e Nova Zelândia e compromissos firmados em relação a preços com Argentina e Uruguai (MAIA et al, 2013).

O desenvolvimento e adoção de políticas voltadas ao meio rural e uma distribuição de renda descentralizada dos grandes centros urbanos no território gaúcho são elementos importantes para a construção de um modelo de desenvolvimento econômico que garanta maior qualidade de vida a população do RS, pois tais medidas não impactam somente no âmbito do desenvolvimento rural (NETO, BASSO, 2005).

\section{Considerações finais}

Este artigo apresentou uma revisão sistemática de publicações sobre a produção de leite no Brasil e, em especial, sobre a bovinocultura leiteira no Estado do Rio Grande do Sul, levantando seu histórico recente e principais características.

A busca de publicações ocorreu através das plataformas Scielo, Periódicos CAPES, Directory of Open Access Journals (DOAJ), Pesquisa Agropecuária - Embrapa e Publicações da Fundação de Economia e Estatística (FEE) sendo realizada a seleção de 28 publicações.

A análise revelou que $89,29 \%$ das publicações são provenientes de estudos realizados no Brasil, sendo o restante $(10,71 \%)$ proveniente da Romênia e Venezuela.

O estudo permitiu constatar que a produção de leite no Brasil representa um importante fator na geração de empregos e distribuição de renda, conseguindo substancial crescimento durante a última década e consolidando-se como uma das atividades essenciais da agropecuária brasileira. A produção de leite encontra seus maiores volumes na Região Sul do país, constituída pelos Estados do Rio Grande do Sul, Paraná e Santa Catarina, onde predominam pequenas propriedades com mão de obra de base familiar. 
Com uma concentração de $75 \%$ de publicações entre 2005-2015, evidencia-se a importância que pesquisas relacionadas a produção leiteira possuem, uma vez que o contexto onde os consumidores brasileiros estão cada vez mais exigentes em relação a qualidade do produto oferecido, gerando a necessidade de investigações relacionadas a melhorias na nutrição do rebanho, sistemas de produção e coleta, produtividade do rebanho, processamento, entre outras carências identificados na cadeia nacional de produção leiteira.

Também foi possível constatar a importância da cadeia leiteira para o Estado do Rio Grande do Sul, onde a produção de leite tem aumentado em todas as regiões nos últimos anos, principalmente em regiões onde predominam a existência de cooperativas de produtores, consequentemente, organizando-se de forma mais qualificada.

O estudo mostrou que no Estado do Rio Grande do Sul predominam os sistemas de agricultura familiar na produção de leite, sendo o produto coletado por laticínios que o processam. Porém, há diversidade de olhares sobre temas ligados a cadeia produtiva do leite, seja no RS ou em âmbito nacional. Autores como Portela et al (2002), Bueno et al (2004) Silva et al (2008) e Lopes, Santos e Carvalho (2012) enfatizam estudos relacionados a viabilidade econômica da produção leiteira; outros concentram estudos em análises relacionadas a qualidade do leite e melhorias no rebanho, como Zanela et al (2006), Silva et al (2011), Noro et al (2006) e Gonzalez et al (2004); alguns autores suscitam questões relacionadas ligadas a cadeia láctea e o encadeamento de complexos industriais e seu impacto sobre a produção leiteira, sendo estes Castro et al (1998), Montoya e Finamore (2005) e Maia et al (2013); a importância dos sistemas de agricultura familiar para o desenvolvimento social e distribuição de renda, além de características desse grupo, receberam ênfase de Wagner, Gehlen e Wiest (2004), Couto (2003), Neto e Basso (2005), Casari e Tormem (2011), Montoya e Finamore (2010), Jantsch et al (2011), Gobbi e Pessoa (2009) e Rodrigues e Alban (2013).
Por fim, o estudo demonstrou que a maioria das publicações selecionadas salientam a importância do sistema de produção de base familiar para a cadeia leiteira nacional, principalmente pelo desenvolvimento que gera nas regiões em que ocorre. No entanto, afirmam a necessidade de investimentos buscando qualificar o leite produzido.

\section{Referências}

BERRO, R. et al. Sistema local de produção de leite em Itaqui, Rio Grande do Sul: caracterização e diferenciação dos estabelecimentos formais. $7^{0}$ Encontro de Economia Gaúcha - FEE, Porto Alegre, 2014. Disponível em <http://www.fee.rs.gov.br/wpcontent/uploads/2014/05/201405237eeg-mesa5producaoleiteitaqui.pdf $>$. Acesso em 21 jun. 2016.

BUENO, P. R. B, et al. Valor econômico para componentes do leite no Estado do Rio Grande do Sul. Revista Brasileira de Zootecnia, Viçosa, v33, n.6, p. 2256-2265, 2004. Disponível em < http://www.scielo.br/pdf/rbz/v33n6s3/23427.pdf >. Acesso em 23 jun. 2016.

CASARI, P.; TORMEM, P. Atividade leiteira agricultura familiar e desenvolvimento regional: estudo de caso da Linha Tormem, Chapecó-SC. Revista Estudos do CEPE, Santa Cruz do Sul, n. 34, p. 139-171, jul-dez., 2011. Disponível em $<$ https://online.unisc.br/seer/index.php/cepe/articl e/viewFile/936/1687>. Acesso em 23 jun. 2016.

CASTRO, C.C. et al. Estudo da cadeia láctea do Rio Grande do Sul: uma abordagem das relações entre os elos de produção, industrialização e distribuição. Revista de Administração Contemporânea, v.2, n.1, p. 143-164, Jan/Abr. $1998 . \quad$ Disponível em <http://www.scielo.br/pdf/rac/v2n1/v2n1a09.pdf >. Acesso em 23 jun. 2016.

CORRÊA, C. C. et al. Dificuldades enfrentadas pelos produtores de leite: um estudo de caso realizado em um município de Mato Grosso do Sul. Anais 48ํㅡㄹ Congresso da Sociedade Brasileira de Economia, Administração e Sociologia Rural. Campo Grande, MS, 2010. Disponível em < http://www.sober.org.br/palestra/15/935.pdf> Acesso em 22 jun. 2016.

COSTA, V. S. et al. Análise de custos a partir da cadeia do valor do leite e seus derivados na região Seridó do Rio Grande do Norte. Revista Ambiente Contábil, Natal, v.7, n.1, jan-jun., 2015. Disponível em <http://periodicos.ufrn.br/ambiente/article/view/56 02/5060 >. Acesso em 25 jun. 2016. 
COUTO, A. T. Agricultura familiar e produção leiteira: análise do sector cooperativo leiteiro da região norte de Portugal e do setor familiar produtor de leite no sul do Brasil. Boletim Goiano de Geografia. Goiânia, v.23, n.2, jul-dez, 2003. Disponível em <https://revistas.ufg.br/bgg/article/view/4178/367 2>. Acesso em 23 jun. 2016.

CRESWEL, J.W. Projeto de Pesquisa - Métodos qualitativo, quantitativo e misto. 3. ed. Porto Alegre: Artmed, 2010.

EMPRESA BRASILEIRA DE PESQUISA AGROPECUÁRIA - EMBRAPA. Gado do Leite Importância Econômica. Disponível em <https://sistemasdeproducao.cnptia.embrapa.br/ FontesHTML/Leite/LeiteCerrado/importancia.htm I> Acesso em 24 jun 2016.

FAUTH, E. M.; FEIX, R. D.. Aglomeração produtiva de laticínios nos Coredes Fronteira Noroeste e Celeiro. Porto Alegre: FEE, 2015. Relatório do Projeto Estudo de Aglomerações Industriais e Agroindustriais no RS. Disponível em $<$ http://www.fee.rs.gov.br/wpcontent/uploads/2016/06/201606068-laticiniosfronteira-noroeste-e-celeiro-relatorio1.pdf> Acesso em 25 jun. 2016.

FERNANDES, E .N; BRESSAN, M.; VERNEQUE, R. S. Zoneamento da pecuária leiteira da região sul do Brasil. Ciência Rural, Santa Maria, v.34, n.2, p. 468-491, mar-abr. 2004. Disponível em <http://www.scielo.br/pdf/cr/v34n2/a23v34n2.pdf $>$ Acesso em 26 jun. 2016.

FOOD AND AGRICULTURE ORGANIZATION OF THE UNITED NATIONS (FAO). Dairy Production and Products - Milk Production. Disponível em $<$ http://www.fao.org/agriculture/dairygateway/milk-production/en/\#.V3AZwbgrLIV> Acesso em 24 jun. 2016.

FRANÇA, F. M. C. Et al. Indicadores da viabilidade financeira e econômica do sistema de produção familiar de leite de cabra no Rio Grande do Norte. Anais da Semana da Caprinocutura e da Ovinocultura Brasileiras, 5, Campo Grande, MS. $2006 . \quad$ Disponível em $<$ http://ainfo.cnptia.embrapa.br/digital/bitstream/it em/36643/1/AAC-Indicadores-deviabilidade.PDF> Acesso em 22 ju. 2016.

GOBBI, W; A. O; PESSOA, V. L. S. A pecuária leiteira e a agricultura familiar em Ituiutaba (MG): as transformações na comunidade da Canoa. Geo UERJ, Rio de Janeiro, ano 11, v.1, n.19, 1은 semestre, p. 79-110, 2009. Disponível em $<$ http://www.e-

publicacoes.uerj.br/index.php/geouerj/article/view /1405/1195.> . Acesso em 22 jun. 2016.

GONZALEZ, H. L. et al. Avaliação da qualidade do leite na bacia leiteira de Pelotas, RS. Efeitos dos meses do ano. Revista Brasileira de Zootecnia,
Viçosa, v. 33, n.6, p.1531-1543, 2004. Disponível em

<http://www.scielo.br/pdf/rbz/v33n6/a20v33n6.pd f> Acesso em 23 jun. 2016.

JANTSCH, E. M. et al. Caracterização da atividade leiteira em sistemas de produção de base familiar na região noroeste do Rio Grande do Sul. Anais do Salão do Conhecimento e XII Jornada de Extensão UNIJUì, ljuí, RS. 2011. Disponível em $<$ http://ainfo.cnptia.embrapa.br/digital/bitstream/it em/50336/1/Artigo-nos-anais.pdf >. Acesso em 03 out. 2016.

LOPES, M. A.; SANTOS, G.; CARVALHO, F. M. Comparativo de indicadores econômicos da atividade leiteira de sistemas intensivos de produção de leite no Estado de Minas Gerais. Rev. Ceres, Viçosa, v. 59, n.4, p. 458-465, julago, 2012. Disponível em <http://www.scielo.br/pdf/rceres/v59n4/05.pdf>. Acesso em 23 jun. 2016.

MAIA, G. B. S. et al. Produção leiteira no Brasil. BNDES Setorial, Rio de Janeiro, v.37, p. 371398, 2013. Disponível em < http://www.bndes.gov.br/SiteBNDES/export/sites/ default/bndes_pt/Galerias/Arquivos/conheciment o/bnset/

set3709.pdf.> Acesso em 24 ju. 2016.

MILKPOINT. Giro Lácteo. Disponível em <http://goo.gl/ywVzYy> Acesso em 26 jun. 2016.

MONTOYA, M. A.; FINAMORE, E. B. Delimitação e encadeamento de sistemas agroindustriais: 0 caso do complexo lácteo do Rio Grande do Sul. Econ. Aplic., Ribeirão Preto, n. 9 (4), p. 663-682, out-dez, 2005. Disponível em <http://www.scielo.br/pdf/ecoa/v9n4/v9n4a08>. Acesso em 22 jun. 2016.

MONTOYA, M. A.; FINAMORE, E. B. Características dos produtores de leite do RS: uma análise a partir do Corede Nordeste. Indic. Econ. FEE, Porto Alegre, v. 37, n. 4, p. 213-224, 2010. Disponível em <http://revistas.fee.tche.br/index.php/indicadores/ article/view/2348/2784> Acesso em 22 jun. 2016.

NETO, B. S.; BASSO, D. A produção de leite como estratégia de desenvolvimento para o Rio Grande do Sul. Desenvolvimento em questão,3(5), 53-72. 2005. Disponível em <http://www.redalyc.org/pdf/752/75230504.pdf> Acesso em 22 jun 2016.

NORO, G. et al. Fatores ambientais que afetam a produção e a composição do leite em rebanhos assistidos por cooperativas no Rio Grande do Sul. Revista Brasileira de Zootecnia, v.35, n.3, p.1129-1135, 2006. Disponível em <http://www.scielo.br/pdf/rbz/v35n3s0/30727.pdf >. Acesso em 03 out. 2016. 
NÚÑEZ, S. R.; HUELVA, D. C. Una oportunidade agro-exportadora em la industria de lácteos em Chile. AGROALIMENTARIA, Mérida, v.14, n. 27, p. 67-81, julio-diciembre, 2008. Disponível em <http://www.scielo.org.ve/pdf/a/v14n27/art06.pdf $>$ Acesso em 25 jun. 2016.

OLIVEIRA, A. S. et al. Identificação e quantificação de indicadores-referência de sistemas de produção de leite. Revista Brasileira de Zootecnia, Viçosa, v.36, n.2, p.507-516, 2007. Disponível em <http://www.scielo.br/pdf/rbz/v36n2/30.pdf> Acesso em 26 jun. 2016.

POPESCU, A.; ANGEL, E. Considerations upon milk and dairy product production in the U.S.A. Lucrari Stiintifice: Zootehnie si Biotehnologii, Timisoara, v.41, n.1, p.695-701, 2008, Lucrãri stiintifice Disponível em <http://www.spasb.ro/index.php/spasb/article/vie w/1273/1223> Acesso em 25 jun. 2016.

POPESCU, A. Considerations on cattle stock and cow fresh milk production in the EU Countries.Lucrari Stiintifice: Zootehnie si Biotehnologii, Timisoara, v. 44, n.2, p. 508-511, 2011. Disponível em <http://www.spasb.ro/index.php/spasb/article/vie w/717/674> Acesso em 25 jun. 2016.

PORTELA, J. N. et al. Análise econômica de sistemas de produção com bovinocultura de leite da depressão central do Rio Grande do Sul. Ciência Rural, Santa Maria, v.32, n.5, 2002. Disponível em

<http://www.scielo.br/pdf/cr/v32n5/11877.pdf>. Acesso em 23 jun. 2016.

RODRIGUES, L. G.; ALBAN, L. Tecnologias de produção de leite utilizadas no extremo-oeste catarinense. RACE, Revista de Administração, Contabilidade e Economia. v. 12, n. 1, p. 171198, jan./jun. 2013 $<$ http://editora.unoesc.edu.br/index.php/race/artic le/view/1694/pdf>. Acesso em 26 jun. 2016.

SÁ. C. O. Et al. Desenvolvimento sustentável da bacia leiteira de Nossa Senhora da Glória no semi-árido sergipano. Anais Congresso Brasileiro de Agroecologia, 3; Seminário Estadual de Agroecologia, Florianópolis, SC. $2005 . \quad$ Disponível em <http://ainfo.cnptia.embrapa.br/digital/bitstream/ CPATSA/33181/1/OPB225.pdf > Acesso em 22 jun. 2016.

SCHUBERT, M. N. et al. Estratégias competitivas das cooperativismo na cadeia produtiva do leite: o caso da Ascooper, SC. Anais do 47ํㅡㄹ Congresso da Sociedade Brasileira de Economia, Administração e Sociologia Rural, Porto Alegre, RS, 2009. Disponível em <http://www.sober.org.br/palestra/13/104.pdf>. Acesso em 25 jun. 2016.

SILVA, D.A.R et. al. Produção de leite de vacas da raça Holandesa de pequeno, médio e grande porte. Ciência Rural, Santa Maria, v. 41, n.3m p. 501-506, mar. 2011. Disponível em < http://www.scielo.br/pdf/cr/v41n3/a888cr4032.pdf >. Acesso em 26 jun. 2016.

SILVA, H. A. et al. Análise da viabilidade econômica da produção de leite a pasto e com suplementação na região dos Campos Gerais Paraná. Ciência Rural, Santa Maria, v.38, n,2, p. 445-450, mar-abr., 2008. Disponível em <http://www.scielo.br/pdf/cr/v38n2/a24v38n2.pdf >. Acesso em 23 jun. 2016.

SILVEIRA, I.D.B. et al. Simulação da rentabilidade e viabilidade econômica de um modelo de produção de leite em free-stall. Arq. Bras. Med. Vet. Zootec., Belo Horizonte, v.63, n.2, p. 392398. 2011. Disponível em <http://www.scielo.br/pdf/abmvz/v63n2/17.pdf>. Acesso em 26 jun. 2016.

SOUZA, M. P. Agronegócio do leite: características da cadeia produtiva do estado de Rondônia. Revista de Administração e Negócios da Amazônia, v.1, n.1, mai-ago, 2009. Disponível em <http://www.periodicos.unir.br/index.php/rara/arti cle/download/4/1> Acesso em 23 jun. 2016.

WAGNER, S. A.; GEHLEN, I.; WIEST, J. M. Padrão tecnológico de produção familiar de leite no Rio Grande do Sul relacionado com diferentes tipologias. Ciência Rural, Santa Maria, v.34, n.5, p. 1579-1584, set-out, 2004. Disponível em $<$ http://revistas.bvsvet.org.br/crural/article/view/17982/18824>. Acesso em 22 jun. 2016.

ZANELA, M. B. et al. Qualidade do leite em sistemas de produção na região Sul do Rio Grande do Sul. Pesq. agropec. Bras., Brasília, v.41, n.1, p.153-159, jan., 2006. Disponível em <http://www.alice.cnptia.embrapa.br/bitstream/do c/118434/1/41n01a21.pdf.> Acesso em 22 jun. 2016. 